\title{
Three Dimensional Printing by Hot-Melt Extrusion; New Era for Development of Personalized Medicines and Continuous Manufacturing of Pharmaceuticals
}

\author{
Amit Chivate ${ }^{1,2}$, Atul Garkal' ${ }^{1}$ Namdev Dhas ${ }^{1}$, Tejal Mehta ${ }^{1, *}$ \\ 'Department of Pharmaceutics, Institute of Pharmacy, Nirma University, Ahmedabad, Gujarat, INDIA. \\ ${ }^{2}$ Area Marketing Manager, Roquette India Private Limited, Mumbai, Maharashtra, INDIA.
}

\begin{abstract}
The three-dimensional printing is a growing field in engineering, civil constructions and pharmaceutical development. The three-dimensional printing is a one-step continuous process. However, conventional manufacturing is batch by batch process hence the three-dimensional manufacturing is advantageous over conventional manufacturing. The three-dimensional technique is cost effective and time-saving process. The three-dimensional printing is a rising era in the development and manufacturing of pharmaceuticals such as medical devices, oral dosage forms and some modified-release products. The personalized dose adjustment as per patient requirement is easier due to three dimensional printing. Hence, the personalized dosage forms are more preferable for potent drugs to avoid the adverse drug reactions and accuracy of a therapeutic drug. The three-dimensional technique equipped with hot-melt extrusion is recently used for the development of various pharmaceutical products. The fused disposition model is commonly employed for the development of layer by layer products. However, the hot-melt extrusion was previously used in pharmaceuticals for solubility enhancement. Currently ample of applications of hot-melt extrusion is explored in research
\end{abstract}

and one of them is the manufacturing of personalized pharmaceuticals. The dose adjustment and personalized pharmaceutical development will be achieved by three dimensional technique equipped with hot-melt extrusion. There is a wide range of polymeric materials with superior properties available for three-dimensional printing of pharmaceuticals. This review briefly discussed the applications of three-dimensional techniques for pharmaceutical development with suitable examples. The current scenario of the techniques and future perspectives are also discussed.

Key words: Personalized dosage forms, Hot-melt extrusion, Three Dimensional printing, Fabrication of dosage forms, Fused-deposition modeling.

\section{Correspondence}

Dr. Tejal Mehta

Professor and Head-Pharmaceutics, Institute of Pharmacy, Nirma University, S.G. Highway, Chharodi Ahmedabad-382481, Gujarat, INDIA.

Phone no: +91 9879357584

Email: tjshah3@gmail.com

DOI: $10.5330 /$ ijpi.2020.3.43

\section{INTRODUCTION}

The early 1980s Three Dimensional (3D) printing technology was used in chemistry, robotics and optics research. Presently, it is also explored in the development of medical and pharmaceutical products. The first powder based 3D printing technique was used in 1993. ${ }^{1}$

\section{THREE DIMENSIONAL PRINTING OF PHARMACEUTICALS}

Pharmaceutical manufacturing is batch to batch process and it is lengthy and costly process. However $3 \mathrm{D}$ printing is continuous process of manufacturing of pharmaceuticals and it is cost effective and time saving. It is having industrial scalability and thus, could be useful in development of several personalized pharmaceutical dosage forms. The fabrication of novel design is achieved as per the patient requirement via $3 \mathrm{D}$ printing easily. ${ }^{2} 3 \mathrm{D}$ printing is currently used for development of human organ and tissue and printing of medical devices. 3D printing is growing field and having rising applications. ZipDose technology is based on the deposition of solid by drops. It introduces the first 3D printed orally disintegrating tablet of drug-levetiracetam (Spritam ${ }^{\bullet}$ ) in 2016. ${ }^{1}$ ZipDose $^{\oplus}$ technology having advantages over conventional techniques such as high dose loading capacity (1000 mg/ tablet), a wide range of taste masking capacity and rapid disintegration within second. ${ }^{3}$
$3 \mathrm{D}$ printing technique is very simple and robust technique. It is cheaper than the conventional manufacturing process for development of pharmaceutical products. 3D printing is used for development of customized designed products as per patient requirement i.e. Development of personalized dosage forms. ${ }^{2} 3 \mathrm{D}$ printing is a flexible alternate technique to the conventional method of tablet compression. There are different printing techniques such as i) 3D printing inkjet printing, ii) thermal inkjet printing, iii) selective laser sintering, iv) stereolithography v) syringe or extrusion $3 \mathrm{D}$ printing. ${ }^{3} 3 \mathrm{D}$ printing is preferred in manufacturing of aerospace, automotive and consumer goods industries. In 2015 first $t$ drug manufactured by using 3D printing is approved by the FDA. ${ }^{4}$ This is strong proof for development of new pharmaceutical products using $3 \mathrm{D}$ printing. It is also called as solid form of fabrication/ rapid prototyping/ additive manufacturing. Unprinted material may be reused in continuous processing. ${ }^{5}$

\section{Three Dimensional Printing manufacturing technology vs traditional manufacturing}

As compared to conventional methods of product development $3 \mathrm{D}$ printing is flexible. It creates personalized complex products. ${ }^{1}$ In Raw material Printing, the raw material is poured layer by layer as per the defined design and automatically solidified to get the desired product. 
Later, the printing designed products may be further processed like polishing, drying, sintering. ${ }^{5}$

\section{STEPS INVOLVED IN HOT-MELT EXTRUSION THREE DIMENSIONAL PRINTING}

1. Dosage form design: Computer design aided software is used for designing expected objects. The selected design need to be as a machine-readable format. ${ }^{1,5}$

2. Preparation of raw materials: Raw material processed maybe in the form of powders, particles, pastes, filaments, binder solution or granules. ${ }^{1,5}$

3. Hot-melt extruded filaments preparation: The polymer and drug heated specific temperature to produces melted filament. The melted filament is moldable as per the design.

4. 3D printing: The material poured layer by layer as per the defined design and automatically solidified to get the desired product. ${ }^{1,5}$

5. Finishing: Later the printing designed products may be further processed like polishing, drying, sintering. ${ }^{1,5}$

\section{FUSED DISPOSITION MODELING}

Fused disposition modeling (FDM) is a leading 3D technique employed in the continuous manufacturing of pharmaceutical products and it works based on HME. It is also named as fused filament fabrication (FFF) because the filament of printing material was poured into the hot nozzle followed by depositing the layer by layer on the printing table. It is suitable for various s printing materials and can be molded in specific size and shape. FDM is applicable for manufacturing of tablets, films, implants, etc. Numerous polymers are recommended as film formers, some suitable examples includes methacrylic acid copolymers such as (Eudragit ${ }^{\circ}$ RL, Eudragit ${ }^{\oplus}$ L, Eudragit ${ }^{\circ}$ RL-PO), cellulose derivatives (HPMC, HPC, HPMCAS), polyvinyl alcohol (PVA), Soluplus ${ }^{\circ}$-polyvinyl caprolactam-polyvinyl acetate-polyethylene glycol graft copolymer using HME. Water-soluble polymers are generally used for the improvement of bioavailability of poorly soluble drugs (BCS class II and IV). ${ }^{6} \mathrm{FDM}$ is mostly used for the development of porous scaffolds for biomedical applications. ${ }^{7}$ In FDM, the melted polymer deposited layer by layer in predefined manner working on the principle of the melted polymer where deposited layer by layer in a predefined manner. FDM heated polymeric material is extruded through a small orifice normally 50-100 $\mu \mathrm{m}$. followed by cooling and solidified on the build plate. ${ }^{8}$

\section{PHARMACEUTICAL APPLICATIONS OF THREE DIMENSIONAL PRINTING}

3D printing has a wide range of pharmaceutical applications. It is not only limited to the development of pharmaceutical drug products but also preferred in tissue culture and medical devices. (Table 1 and Figure $1)^{5}$

\section{a. Manufacturing of Oral tablets}

Pietrzak, I et al. Prepared flexible-dose of immediate-release and extended-release tablets by using FDM 3D printing and HME. The designed tablets are genuine and easy to swallow. The crystalline thermostable theophylline was loaded in 3D printed polymeric tablet matrix. ${ }^{3}$

\section{b. Orodispersible films}

Orodispersible films are solid films that rapidly disintegrate and dissolve in the mouth. It has recommended to those patients who have swelling problems and want to improve patient compliance. It is also having advantages over conventional tablets like avoidance of drug first-pass metabolism. ${ }^{6}$ Musazzi et al. prepared personalized orodispersible films of paracetamol maltodextrins by using HME 3D printing technology. The RMA extruder was preferred for the extrusion of materials. Maltodextrins plus paracetamol was mixed and glycerin is used as a wetting agent. Wetted material was extruded by using RAM extruder followed by $3 \mathrm{D}$ printing of orodispersible films on packing material.9.14 Jamróz et al. prepared an orodipersible film of poorly water-soluble drugaripiprazole for improvement of dissolution rate. After the processing, aripiprazole is converted into amorphous form in product as confirmed by XRD data. The designed film is porous in nature hence an increased dissolution rate. This study proves that the FDM is a suitable technique for the preparation of orodispersible films. PVA was used as a polymer for drug loading. PVA is a water-soluble polymer having matrix-forming capacity by HME. From this case, the study author concludes that FDM is a suitable method for the fabrication of orodispersible films by using 3D printing and HME. ${ }^{6,15}$

\section{c. Medical Devices}

Common methods for the preparation of medical devices: injection molding, melt-extrusion, freeze-drying, solvent casting and compression molding. ${ }^{7,16,17}$

\section{d. Implants}

3D printing using FDM is recently developed for the manufacturing of implantable drug delivery devices. This technique is commonly used for the preparation of intravaginal rings, subcutaneous rods, intrauterine devices, etc.

\section{e. Gastro retentive drug delivery systems}

Dumpa, Bandari and Repka designed core-shell gastro retentive pulsatile tablets of theophylline by using HME fused with FDM 3D printing techniques. The filament generated through HME fused with FDM 3D printing was used for direct compression and the final product was coreshell tablets..$^{10,18,19}$

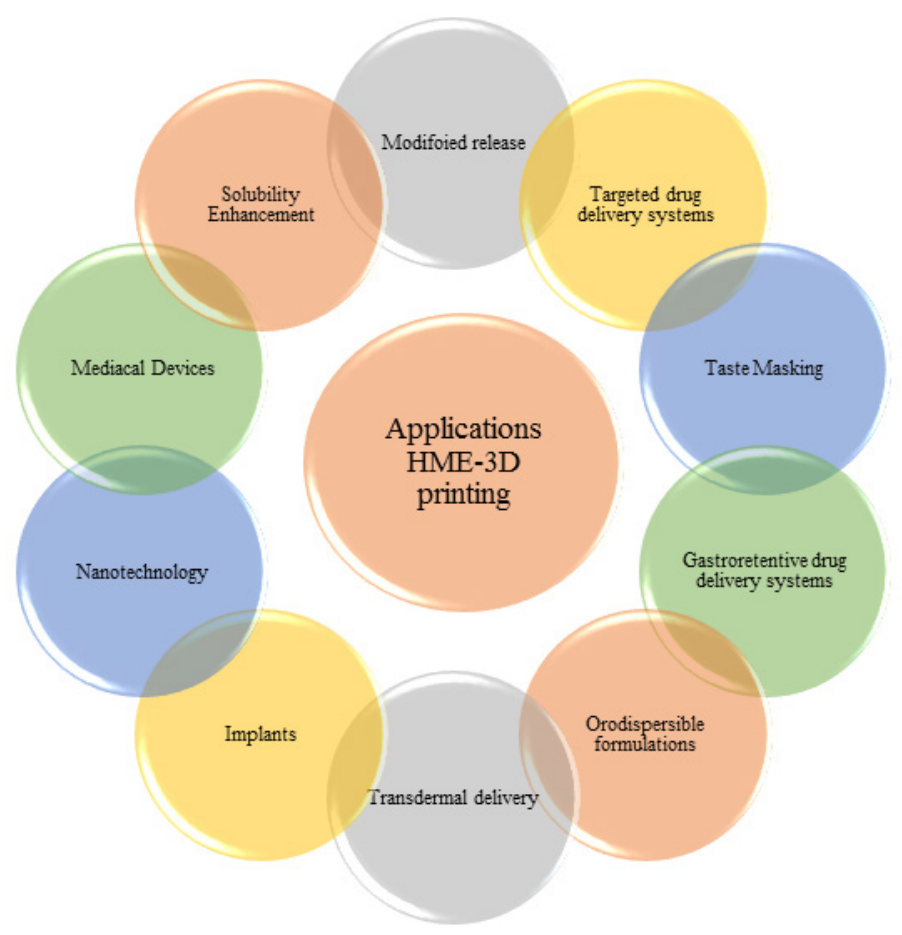

Figure 1: Different Applications of HME-3D printing. 
Table 1: Different products developed by using 3D printing with HME.

\begin{tabular}{|c|c|c|c|c|c|c|}
\hline Formulation & $\begin{array}{c}\text { Route of } \\
\text { administration }\end{array}$ & Drug & Excipients & Application & Technology & Reference \\
\hline $\begin{array}{l}\text { Orodispersible } \\
\quad \text { films }\end{array}$ & Oral & Paracetamol & Maltodextrins & $\begin{array}{c}\text { Personalized } \\
\text { orodispersible films }\end{array}$ & $\begin{array}{l}\text { HME 3D } \\
\text { printing }\end{array}$ & 9 \\
\hline $\begin{array}{l}\text { Orodispersible } \\
\text { films }\end{array}$ & Oral & aripiprazole & PVA & Solubility enhancement & FDM & 6 \\
\hline Tablets & Oral & fluorescein & PVA & $\begin{array}{c}\text { Personalized } \\
\text { Controlled release tablet }\end{array}$ & $\begin{array}{l}\text { Fused-filament } \\
\text { 3D printing }\end{array}$ & 1 \\
\hline Tablets & Oral & theophylline & $\begin{array}{l}\text { Hydroxypropyl } \\
\text { cellulose, ethyl } \\
\text { cellulose }\end{array}$ & $\begin{array}{l}\text { Gastroretentive and } \\
\text { pulsatile drug delivery } \\
\text { systems }\end{array}$ & $\begin{array}{l}\text { HME and FDM } \\
\text { 3D Printing }\end{array}$ & 10 \\
\hline
\end{tabular}

\section{f. Polymers}

Properties of superior polymers for 3D printing by using HME; It should be thermoplastic, it should be sufficient rigidity to mould and allow to form a filament of specific predefined dimensions before printing. Cyclodextrin- water-soluble polymer used for improvement of solubility. PVA has the capacity to form a matrix as well as it is water-soluble hence used for the improvement of drug solubility. ${ }^{6,19}$

\section{DISCUSSION}

$3 \mathrm{D}$ printing is advanced technology and it forms the object as per requirement by layer-by-layer technique During the development of pharmaceutical dosage forms, the continuous manufacturing is a very important consideration because of cost-effectiveness and increase productivity. In the current manufacturing process, the pharmaceuticals are manufactured in lots or batches. However, it varies the product specifications and quality. But the formulations developed using novel $3 \mathrm{D}$ printing technology is a continuous process and it would be cost-effective and produces uniform quality products. Recently it is applied in several areas like engineering, construction, aerospace, automotive, medical and pharmaceutical sectors. More specifically in the pharmaceuticals it is applicable for the manufacturing of medical devices and some complicated pharmaceutical products. However, the scope of these techniques is increasing towards the productions of personalized dosage forms. The need for personalized dosage forms may fulfill by $3 \mathrm{D}$ printing with HME. The manufacturing of pharmaceutical tablets was achieved by $3 \mathrm{D}$ printing in the future. The $3 \mathrm{D}$ printing is approved by the FDA and the first ZipDose technology successfully works on the basis deposition of solids by drops. In the view of simplicity, robustness and cost-effectiveness and thus. Advantageous over the commercial manufacturing of pharmaceutical products. It is a promising flexible technology that offers the design of formulations, which is complicated to develop by conventional technique. Morevoer, it allows the preparation of various dosage forms with high accuracy of Active Pharmaceutical Ingredient and excipients concentrations, as compared to the traditional pharmaceutical manufacturing process. It allows for creating multifunctional multidrug devices, drug delivery systems and drug dosage formulations for personalized use.

\section{CONCLUSION}

The formulation of medical devices and pharmaceutical products using $3 \mathrm{D}$ printing technology is a promising new era worldwide. The majority of patients prefer the personalized dosage forms of medicines however the manufacturing of personalized medicine is only feasible using the $3 \mathrm{D}$ printing techniques. The hot-melt extrusion is the advanced, industrially scalable and cost-effective method for 3D printing of materials. Looking to the ample of opportunities and versatlality, it is predicted that the conventional techniques of manufacturing of pharmaceutical dosage forms will be augmented by by $3 \mathrm{D}$ printing in near future.

\section{ACKNOWLEDGEMENT}

Authors would like to thank Nirma University for providing financial assistance in the form of Nirma University stipend-JRF (NU/Ph.D./IP/ GAD /19-20/1496) to Atul Garkal.

\section{CONFLICT OF INTEREST}

Authors report no conflict of interest.

\section{ABBREVIATIONS}

3D: Three dimensional; HME: Hot-Melt Extrusion; FDA: Food and Drug Administration; FDM: Fused deposition modeling; FFF: Fused filament fabrication; BCS: Biopharmaceutical Classification Systems.

\section{REFERENCES}

1. Zhang J, Feng $X$, Patil $H$, Tiwari RV, Repka MA. Coupling 3D printing with hotmelt extrusion to produce controlled-release tablets. Int J Pharm. 2017;519(12):186-97.

2. Smith DM, Kapoor Y, Klinzing GR, Procopio AT. Pharmaceutical 3D printing Design and qualification of a single step print and fill capsule. Int $\mathrm{J}$ Pharm. 2018;544(1):21-30.

3. Pietrzak K, Isreb A, Alhnan MA. A flexible-dose dispenser for immediate and extended release 3D printed tablets. Eur J Pharm Biopharm. 2015;96:380-7.

4. Deshmukh S, Avachat A, Garkal A, Khurana N, Cardot JM. Optimization of a dissolution method in early development based on IVIVC using small animals: Application to a BCS class II drug. Dissolution Technol. 2016;23(4).

5. Norman J, Madurawe RD, Moore CMV, Khan MA, Khairuzzaman A. A new chapter in pharmaceutical manufacturing: 3D-printed drug products. Adv Drug Deliv Rev. 2017;108:39-50.

6. Jamróz W, Kurek M, Łyszczarz E, Szafraniec J, Knapik-Kowalczuk J, Syrek $\mathrm{K}$, et al. 3D printed orodispersible films with Aripiprazole. Int J Pharm. 2017;533(2):413-20.

7. Mehta TA, Shah N, Parekh K, Dhas N, Patel JK. Surface-Modified PLGA Nanoparticles for Targeted Drug Delivery to Neurons. In: Surface Modification of Nanoparticles for Targeted Drug Delivery. Cham: Springer International Publishing. 2019:33-71.

8. Tsouknidas A. Friction Induced Wear of Rapid Prototyping Generated Materials: A Review. Adv Tribol 2011.

9. Dhas NL, Kudarha RR, Mehta TA. Intranasal Delivery of Nanotherapeutics/ Nanobiotherapeutics for the Treatment of Alzheimer's Disease: A Proficient Approach. Crit Rev Ther Drug Carr Syst. 2019;36(5):373-447.

10. Pandey A, Singh D, Dhas N, Tewari AK, Pathak K, Chatap V, et al. Complex injectables. In: Delivery of Drugs. Elsevier. 2020;191-213.

11. Pandey A, Dhas N, Deshmukh P, Caro C, Patil P, García-Martín ML, et al. Heterogeneous surface architectured metal-organic frameworks for cancer therapy, imaging and biosensing: A state-of-the-art review. Coord Chem Rev. 2020;409:213212.

12. Dhas NL, Kudarha RR, Acharya NS, Acharya SR. Polymeric Immunonanoparticles Mediated Cancer Therapy: Versatile Nanocarriers for Cell-Specific Cargo Delivery. Crit Rev Ther Drug Carr Syst. 2018;35(1):1-64.

13. Dhas NL, Raval NJ, Kudarha RR, Acharya NS, Acharya SR. Core-shell nanopar- 
ticles as a drug delivery platform for tumor targeting. In: Inorganic Frameworks as Smart Nanomedicines. Elsevier. 2018;387-448.

14. Amit C, Viral P, Prakash SO, Atul G. Application and Functional Characterization of Kollicoat Smartseal 30D as a Solid Dispersion Carrier for Improving Solubility. Asian J Pharm. 2020;14(2):1-9

15. Dhas N, Parekh K, Pandey A, Kudarha R, Mutalik S, Mehta T. Two dimensional carbon based nanocomposites as multimodal therapeutic and diagnostic platform: A biomedical and toxicological perspective. J Control Release. 2019;308:130-61.

16. Genina N, Holländer J, Jukarainen H, Mäkilä E, Salonen J, Sandler N. Ethylene vinyl acetate (EVA) as a new drug carrier for 3D printed medical drug delivery devices. Eur J Pharm Sci. 2016;90:53-63.

17. Goyanes A, Buanz ABM, Basit AW, Gaisford S. Fused-filament 3D printing (3DP) for fabrication of tablets. Int J Pharm. 2014;476(1):88-92.

18. Musazzi UM, Selmin F, Ortenzi MA, Mohammed GK, Franzé S, Minghetti $P$, et al. Personalized orodispersible films by hot melt ram extrusion 3D printing. Int J Pharm. 2018;551(1-2):52-9.

19. Dumpa NR, Bandari S, Repka MA. Novel gastroretentive floating pulsatile drug delivery system produced via hot-melt extrusion and fused deposition modeling 3D printing. Pharmaceutics 2020;12(1).

Article History: Submission Date : 18-03-2020; Revised Date : 08-05-2020; Acceptance Date : 27-07-2020.

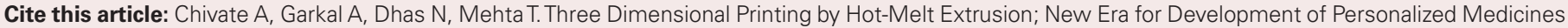
and Continuous Manufacturing of Pharmaceuticals. Int. J. Pharm. Investigation. 2020;10(3):233-6 